\title{
La Iglesia y los cristianos, sacramento del mundo
}

\section{A. EL CRISTIANO EN SÜ CRISTIANISMO}

Lo que caracteriza, sacralizando al mundo, al cristianismo no es su doctrina, sino el autor de esa doctrina. O mejor y más claro. Lo peculiar del cristianismo, y que ninguna religión anterior o posterior tuvo ni ha tenido, es el hecho real e histórico de que Dios mismo se plantó en nuestro orden humano o si se quiere, en medio de nuestro desorden terreno y humano.

San Agustín dice que Dios se hizo hombre para que el hombre fuera Dios. Dios se hizo carne y hueso de hombre; y vivió a lo hombre. Ese Dios que no cabe en la estructura del mundo, sino que la trasciende, ha bajado hasta nosotros y tomó forma de criatura humana. Pero, por eso mismo, por trascender nuestras estructuras creadas, fue posible su descenso a la llanura en que pululan los hombres. Y ha entrado en ella, permaneciendo sólo al margen de una única cualidad humana, ajeno al pecado. En lo demás idéntico a los demás seres humanos.

Así, Cristo, el Cristo objeto de nuestra religión, entró en nuestra historia, y es historia estupenda de la humanidad. Más aún : es el que da sentido e intencionalidad a todo lo largo y ancho de la existencia de la humanidad.

Cristo se presenta al mundo como arranque, medio y fin de un profundo misterio, que, asentándose en el tiempo, lo sobrepasa y explica. Ese misterio es el plan de salvación, que Dios se formó desde el primer atisbo de desorden original y originario en el mundo. En cada acto - pensamiento - palabra de Cristo - Historia - Hombre - Dios ha realizado un gesto de salvación - reparación - redención. Porque este 
Cristo-Hombre, al ser al mismo tiempo Dios, todos sus actos humanos se realizaban desde la perspectiva divina de salvación, y tenían algo más que una pura cualidad humana de acción y de mérito.

Esto es lo maravilloso de Cristo, que, estando sobre el tiempo y por encima de la histo:ia, se implanta en el tiempo y se hace también historia, hasta tal punto que sólo El la explica y solamente El la concluye. Luego al ser Cristo Dics y Hombre, todos sus actos se realizan dentro de la perspectiva temporal del gran plan divino de salvación. Este es el misterio, o la revelación de Dios en la historia humana.

El misterio de Cristo no es que trate de explicar o conciliar las esperanzas terrenas con las ultratelúricas, sino de manifestar una doble intencionalidad de perspectiva en la que todo el hombre-humanidad queda inserto en el marco de su propia historia. Y dentro de esa historia humana es donde se realiza el reino de Dios. Así estar-en-elmundo, en donde el hombre es el colorante y el realizante de valores humanos, recibe un sentido profundo y último en el estar-en-Cristo.

De esta manera, el hombre, siendo un ser que peregrina $y$ va, que evoluciona y adelanta, llega por este progreso material y espiritual a poseerse espiritual y humanamente; y es así también cómo llega a realizar plenamente su propio ser en todas sus dimensiones.

Ser cristiano, por tanto, no es una manera de estar-en-el-mundo que se oponga a otras formas de vida y pensamiento. Es más bien una dimensión de largura y anchura, que engloba a todas las otras dimensiones - verticales $\mathrm{u}$ horizontales-, que contengan valores humanos o suprahumanos. Porque, vivida profundamente en Dios, la existencia humana camina hacia un nuevo misterio, y progresa hacia una realidad eterna en la salvación. Camina hacia el reino definitivo de Dios, manifestación final de su amor en el plan divino salvífico.

Lo terreno, por tanto, no es un nuevo paso a la eternidad; es algo más: la base y progreso hacia una realidad eterna en el plan de Dios en la salvación total de la humanidad. Para quien vive en, por y para Cristo lo terreno adquiere una real permanencia, convirtiéndose en el elemento fermentativo de eternidad, o en un ambiente cultural y cultual celestial. Y el cristiano sabe muy bien, que, por lo mismo, nuestra vida en Cristo no será plenamente humana y espiritual más que encaminándola por una escatología, en la que vamos creciendo y amasándonos espiritualmente; y de ese modo también los cielos y la tierra 
van dirigidos hacia esos "nuevos cielos y a esa tierra nueva". Todo eso lo vamos ya preparando en este mundo-historia. No sólo se salvará el alma; tiene que salvarse todo el conjunto nuestro personal, porque somos personas a través de alma y cuerpo. El alma sólo existe como subjetividad cncarnada y en cuanto mantiene una relación con el mundo material dentro de la acorporeidad y por medio de ella. Tiene que salvarse todo el conjunto; de lo contrario, aun si se tratara de una redención simplemente religiosa, sería inacabada e incompleta; no sería una redención del hombre. Porque el hombre lo es en cuerpo y alma; todo junto forma la persona; y la persona es lo que se salva.

El estar-en-el-mundo no significa vivir a ciegas, sino en un medio apto en que yo pueda desarrollar libremente mi capacidad humana. Yo soy un ser que busca, que camina a tientas probando y reprobando, que no estoy conducido por un instinto infalible y natural. Tengo que plantificarme en mi situación, hacerme yo mismo la vida en medio de la circunstancia, a la que tengo que dominar. $\mathrm{Y}$ en todo este mi obrar dudo y titubeo, cambio de postura para insertarme en la que me es auténticamente mía. El riesgo y el fracaso forman parte de mi condición. $Y$ todo esto de este estar-en-Cristo, porque esto no me cambia de condición; pero sí que me ayuda en el camino. La responsabilidad del riesgo y del desastre radica en el hecho fundamental de que soy hombre. $\mathrm{Y}$ esto explica mi fracaso y victoria, cuando salgo triunfante del riesgo y del conflicto.

Cristo, con su muerte y resurrección triunfó de esta situación humana; pero las consecuencias socio-humanas y materiales siguen pesando sobre el estado nuevo de vida en el cristiano. Y el pecado subsiste en el mundo como una peste que avanza.

La ciudad de Dios y la ciudad del mundo se entrecruzan y abocan muchas veces en el choque de fuerzas. Pero siempre hay dos movimientos humanos, aun en cultura, el avance de progreso y el destructivo o de retroceso, y los dos entremezclados. El pecado prolifera como un cáncer profundo y sordo; pero también la virtud adquiere un progreso notable en todas las esferas y estructuras mundanas. $\mathrm{Y}$ a veces los hombres se sienten desbordados por la situación de estos dos tirantes; y parece que la comunidad de los santos fuera arrastrada a la catástrofe; y esto desde siempre. Porque la armonía entre hombre y gracia se realiza a costa de dolorosos esfuerzos y de constantes conflictos. Pero siempre el reino de Dios sigue en avance incesante, con 
la alegria del que se siente conducido por la mano paternal de Dios hacia su reino de justicia y de paz.

Nuestro estar-en-el-mundo nunca tiene que estar en contraposición con el otro nuestro estar-en-Cristo. Las dos situaciones tienen que conjugarse en la armonía de la redención dentro de la gracia.

San Pablo insiste en que pongamos atención a este doble proble. má : elección y no elección, los de dentro y los de fuera, los vocati y los demás. Los vocati, los cristianos llamados escogen en Cristo vivir en el mundo; pro no pertenecen al mundo ${ }^{2}$; pero el peligro de dejarse seducir por él aún subsiste para todos y cada uno de los vocati. San Juan da el grito de alarma: "No améis al mundo, ni lo que hay en él») ${ }^{3}$.

La hora definitiva de salvación no ha sonado aún. Y aún en el mundo tiene que hacerse. "Aún no se ha manifestado lo que seremos" ${ }^{4}$. La hora se hará final con la llegada-aparición del Redentor en su manifestación gloriosa al fin del tiempo-historia. La parusía, la vuelta triunfante de Cristo al mundo será el comienzo de la salvación definitiva, y el comienzo real del reino de Dios.

Luego aún nuestra salvación es objeto de esperanza 5 . Luego también las oportunidades de salvación para el hombre se encuentran dentro de este misterio histórico de Cristo. Y mientras esta parusía no se realice, nuestra redención sigue inacabada dentro del marco temporal de su aplicación a la historia humana. Aún seguirá la humanidad con su humanismo peregrinante, en intensa tensión escatológica. Luego tenemos que ganarnos la salvación a pulso, no cediendo terreno, sino avanzando por el llano y por las quebradas, en derechura al Padre, y palmo a palmo sin perder ninguna posición.

El hecho de la creación - de mi propia creación, en donde Dios se manifiesta en su amor hacia mí- no es más que el comienzo del único plan divino de salvación hacia mí. Al concederme su gracia, no corrige mi creación, la continúa y acrecienta. $Y$ esto que siento y afirmo en mí, sucede en todos y en cada uno de los hombres. Y si en todo

1. Rom. 8, 34

2. Jn. 15,19

3. $1 \mathrm{Jn} .2,15$

4. $1 \mathrm{Jn} .3,2$

5. Rom. 8, 24 
y por todas partes va sintiendo el hombre esta revelación-amor de Dios, lógico es aceptarla sin condiciones, porque ahí está su progreso, su cultura, su arte, su ciencia, su economía y su política humana.

Al aceptar la salvación, parte del hombre una espotánea acción de gracias, como consecuencia de una entrega sin limites a la voluntad salvífica de Dios. $Y$ en esta aceptación va implícita la disponibilidad nuestra para con el amor del Padre, y el reconocimiento de la superioridad absoluta de Dios y de nuestra dependencia en orden a la salvación. Esta humildad humana y evangélica se convierte en orgu1lo, en timbre de gloria: isoy hijo de Dios, y Dios es mi Padre bondadoso!

Una objeción. ¿Entonces el mal, eso que impide llevar a cabo el plan divino de salvación? El mal no lo hizo Dios; es incapaz de hacerlo porque si lo hubiera lanzado al mundo, Dios no sería Dios. El mal lo hizo, lo hace, lo hará siempre la voluntad humana en rebeldía con Dios. Más aún: incluso la muerte de Cristo es obra de la libertad y del pecado del hombre.

Si hasta podemos afirmar que el pecado-mal reina en el mundo, también podemos decir que hay una porción inmensa en la que reina a plenitud el amor: la Iglesia. "Cristo amó a su Iglesia y se entregó El mismo por ella, con el fin de santificarla y purificándola con el bautismo del agua con la palabra que la acompaña, para presentar ante sí mismo esta su Iglesia gloriosa sin mancha ni arruga ni cosa pareci$\mathrm{da}$, sino santa e inmaculada) ${ }^{6}$.

\section{B. EL CRISTIANISMO Y LA IGLESIA, SIGNOS DE SALVACIÓN}

La gracia de la salvación es en realidad una gracia redentora, que ampara, protege y libera al hombre del mal. Aun el fracaso relativo que viene del mal, lo mismo que el triunfo del mal, pueden quedar encuadrados y transformados por el amor creador y redentor de Dios en instrumentos de gracia, y siempre en campo de redención humana, - en aplicación de los méritos de Cristo-Redentor a los hombres. La energía del plan de salvación de Dios está en que siempre está por en-

6. Ef. 5, 25-27. 
cima de todos los fracasos y estragos que pueda introducir en él la libertad humana.

Es lo que hizo Cristo en medio de una masa empecatada y condenada a la miseria, al sufrimiento, a la muerte: romper el aguijón de la muerte y del pecado. Entonces el poder del pecado quedó convertido en posibilidad de salvación. $\mathrm{Y}$ si la muerte de Cristo a los ojos de los hombres fue un crimen, un deicidio, para el propio Jesús fue un abandono lleno de amor, humildad y obediencia en las manos del $\mathrm{Pa}$ dre. La victoria aparente de las fuerzas del mal y el fracaso aparente del mismo Cristo, en realidad fueron para El y para la humanidad entera un triunfo definitivo sobre el pecado y la misma muerte.

Luego, a veces también y según los planes de Dios, el fracaso relativo en el bien, tiene un valor salvífico, porque, de rebote, nos coloca en más intimidad con Dios. Bien claro lo dice San Agustín: «hasta el final de los tiempos la Iglesia prosigue su peregrinación en medio de las persecuciones (de las potencias del mal) del mundo y de los enemigos de Dios).

La gran capacidad del hombre es sentirse en disposición de aceptar, de recibir la gracia de la cruz, porque ésta se introduce dentro del vacío de sí para una plenitud de Dios, con lo que el hombre cobra bríos para una formidable audacia de construcción propia y de edificación para los demás. Esta gracia de la cruz-redención nos coloca en la disponibilidad para el trabajo heroico de humanización-divinización del mundo. Esta es una responsabilidad que el cristiano echó sobre sí mismo el día de su bautismo y que réorzó en el sacramento de su confirmación. Si como hombre, con su humanismo, ya siente la responsabilidad de responder por su hermano, como cristiano, con su cristianismo, se compromete con él a hacer de redentor.

Como hombre se da cuenta que el mundo está al borde del caos. $Y$ como cristiano sabe que el mundo todavía puede ser salvado; y a salvarlo dedica todo el fondo de sus energías humanas, sabiendo que no trabaja sólo por el mundo sino que con él trabajan también todos los cristianos de la Iglesia, y Cristo mismo, que empeñó su palabra y se quedó con el cristiano hasta el final de los tiempos. Con Cristo y por Cristo el cristiano hará del mundo un nuevo cosmos, un orden nuevo dentro de una belleza eterna. Y sabe, además, el cristiano que él tiene un centro de donde partirá hacia la salvación del mundo: Cris- 
to-Sacrificio-y-Sacrificador, Cristo-Víctima es el lugar-centro de donde brota el orden de la nueva creación. Puesto que Cristo ha sido crucificado en beneficio de todos y de todo; y en todas las cosas imprimió la señal de su cruz, que será también el signo de todo el mundo, crando todo vielva a Cristo, en la magna recapitulación de que nos habla San Pablo?.

La Iglesia, como depositaria del sacramentum mundi, Iglesia de Cristo, al realizar en el mundo la gracia, al mismo tiempo hace ver al mundo que el nombre de Dios - eheyeh asher eheyeh- está impreso y vivo en la existencia humana ante el mundo. Por eso, las palabras del Concilio Vaticano II : "La Iglesia es en Cristo como un sacramento o señal e instrumento de la intima unión con Dios y de la humanidad de todo el género humano ${ }^{8}$.

Como depositaria de la gracia y como administradora de la misma, ella se convierte a la vez en sacramento del mundo. Porque ella es el instrumento de unión-unidad-unificación, signo de comunión de toda la humanidad con el Dios vivo. Porque ella es la unidad de los hombres que viven en comunión con Dios, que es la vida, que es $E l$ que es.

Pero hay que tener en cuenta que un sacramento no es sólo signo-símbolo de algo; el sacramento es también realización, señal y signo que realiza-opera. Y como sacramento realiza y obra la unidad, la paz, la justicia de Dios entre los hombres. Es acción unificadora y santificante y santificadora de Dios en este mundo. $Y$ si se nos apura un poco hasta diríamos que es la forma visible de Dios santificando en el mundo. Siendo signo, es al mismo tiempo presencia manifiesta de una comunión ya realizada entre los hombres a través de una metanoia intima y radical, indicadora también de unión vital con el Padre a través de Cristo y por la gracia del Espíritu Santo.

Así, la Iglesia es fundamento de la realidad de la salvación entre los hombres. Si es signo, es también realidad; y, por serlo, es también mediación, porque en ella signo y mediación forman un todo uno en su presencia sacramentaria. Como sacramento, la Iglesia vive y hace vivir en anticipo esa salvación, aunque sin darse en ella la forma con-

7. Ef. 1,10

8. Lumen Gentium, $\mathrm{I}, 1$ 
creta y definitiva, que sólo puede tener cuando la salvación llegue al ápice y consumación al final del tiempo-historia.

Un hombre, intensamente hermano y humano, Cristo-Jesús, dio el sí fecundo al Padre; y El que es el sí o amén operante de Dios ${ }^{9}$, dejó su propia misión humano-divina en la lglesia; y la Iglesia manifiesta constantemente la santificación progresiva del mundo, como realidad humana, por medio también de su sí constante. Y esta santificación del mundo se va insertando y manifestando en la historia profana bajo la forma maravillosa de una historia de amor humano-divina de Cristo al mundo.

Si la Iglesia tiene esta misión de presencia al mundo, si ella respresenta-significa el sí del hombre, de cada hombre a Dios, defraudar este sí de cada uno, que por cada uno da la Iglesia, es alejarse de la misión humana individual-personal por un no culpable a Dios. Rehusar a Jesús es renunciar a la Iglesia; y renunciar a la Iglesia es colocarse fuera del alcance de la salvación, porque es renegar del autor de la misma; es también decirse un no a sí mismo y al mundo.

Orientarse a los demás es ya colocarse del lado de Cristo-Hermano-Hombre, es aceptar el mensaje de salvación evangélica que la Iglesia, enseña y propaga, es pertenecer a la Iglesia, es insertarse en Dios. Porque el pertanecer a li Iglesia entraña una voluntad operante, un querer cambiar la faz del mundo, un hacer por cambiar la faz del mundo para una comunión de amor entre los hombres en Cristo. Es que en el fondo de cada hombre existe una dosis de fe escatológica, que hay que ir suscitando y avivando en cada momento, y que a cada hombre va dando la consciencia de una voluntad decidida de desarrollo en el mundo y del mundo.

Con la llegada de Cristo no se cumplió ya todo. Falta lo de la parte humana, la de cada hombre, la de cada mujer: el insertarse cada uno en la salvación que El regaló a la humanidad. Si Cristo es la promesa-acabada-cumplida, es una promesa que lo renovará todo. Pero a nosotros nos toca hacerla realidad en nuestra intimidad humana y en la intimidad de los demás. Cristo ya dio lo que tenía que dar, se dio plenamente a Sí mismo. De nuestra parte queda aceptar la donación y hacerla entrar en nosotros.

9. 2 Cor. 1,20 
«Puede ser que al hombre de hoy le resulte más difícil descubrir la presencia de Dios en el mundo; sin embargo, la preocupación mayor por asegurar a los demás, sean los que sean, sus oportunidades en la vida, y la repulsa cada vez mayor, inspirada en un sí radical al hom$\mathrm{b}: \mathrm{e}, \mathrm{d}$ e toda forma de discriminación $\mathrm{y}$ de degradación constituyen indudablemente una confesión anónima del sí de Dios al hombre: una glorificación de su nombre. Por eso, incluso en nuestro mundo ateo, Dios está, quizá, más cercano que nunca) ${ }^{10}$.

Pero como Dios se muestra en presencia arropada, la Iglesia destapa a Dios, señalando dónde se le puede encontrar, cómo tiene el hombre que encontrarlo-descubrirlo. Y lo lleva a la fuente misma, lo conduce a Cristo, diciéndole que El es Dios, que El es su Hermano, y que cada hombre es hermano de Cristo, que cada hombre, por eso, es en cierto modo otro Cristo y otro Dios, que el hombre es un dios creado, y que Dios mora en él en las formas de bien, verdad, belleza, justicia, paz, felicidad... Pero el hombre, por su modo actual de ser tiene, frente a la fe, una posibilidad atea, que explica su situación ambigua de cara a Dios. La Iglesia trata de desenmascarar a Dios y de sacar al hombre esa posición de ateísmo, indicándole dónde y cómo está Dios. Lo demás tiene que hacerlo él solo: darse a Dios. Y si no se da, es que algo podrido oculta en su corazón, algo que le tapona la vista, porque a Dios sólo se va de rodillas y con los ojos limpios. ¡ $\mathrm{Di}$ chosos los limpios de corazón y de ojos!

Y ahora una pregunta: ¿qué hacemos los que somos Iglesia para limpiar el corazón de los que lo tienen podrido y para limpiar los ojos de los que los tiene cegados? ¿Qué haces tú, obispo, que tienes la plenitud del sacerdocio y que, por lo mismo, estás más lleno -o debes estarlo- de Dios y de su Espíritu? ¿Qué haces tú, sacerdote, depositario de la gracia sacramental y del misterio de la palabra? ¿Qué haces tú, seglar, que eres tan Iglesia como el papa, los obispos y los sacerdotes? ¿Qué haces por tu hermano de corazón enfermo, por tu hermano que tiene la ceguera de los ojos? ¿No os dais cuenta todos que en vuestras manos está la Iglesia para hacerla caminar y para hacer con ella realidad la salvación de Dios en el plano humano de cada hombre? Nos quejamos del ateísmo moderno, del indeferentismo de nuestra época, ¿y qué hacemos por desterrarlos? Sólo se necesita un

10. E. SCHILLEBEEKX $E l$ mundo y la Iglesia, (Salamanca. 1969), 204 
pcco más de fe y algo más de caridad, que lo demás lo está ya poniendo Dios.

Por más que la Iglesia diga y haga en la voz de sus pastores, por más decisiones conciliares sobre la estructura y funcionamiento de la Iglesia que se nos den, si nosotros no las hacemos caminar, ahí se quedan todas, y la Iglesia no marcha todo lo aprisa que debe hacerlo. Lo que cuenta para agrandar el reino de Dios somos nosotros, nosotros los del reino. $\mathrm{Y}$ si los de dentro no empujamos, la máquina no anda; y los demás se quedan fríos. Lo que debemos hacer para comeñar es pensar y obrar creyendo que la Iglesia es el mundo y que el mundo es Iglesia. Por eso, los que somos Iglesia vivimos nuestro ser-cristiano en el mundo; y nuestra salvación y la de los otros se realiza sólo dentro de nuestro mundo humano.

El punto más fundamental de la fe -después de la creencia en Dios- es el plan divino de salvación, por el que Dios mismo se nos revela y regala en Jesucristo de manera gratuita y absoluta. Y Cristo se convierte así en la única comunicación graciosa, o proximidad absoluta del misterio divino. A través de Cristo se nos manifiestan y regalan nuestras más profundas posibilidades a lo largo de nuestra existencia humana. Más aún: sólo a través de Cristo se nos hacen más claras y más fácilmente comprensibles. Así, la vida de gracia sólo a través de Cristo se puede conseguir y aumentar. Hasta nuestra propia historia humana profana - historia-tiempo de la humanidad-, conservando su expresión humana, queda encuadrada en el ritmo de 10 divino, impregnada por la presencia absoluta y gratuita del misterio de Dios en su amor infinito y desinteresado.

El cristianismo-Iglesia no hace más quie desvelarar este misterio y sacar todas las consecuencias que de él se derivan, a través de la clari, dad de la verdad que emana de Cristo-Dios. En esta proximidad de Dios al hombre, a través de Cristo, la Iglesia enseña y propaga todo lo suyo doctrinal, desde la Trinidad y Encarnación, hasta la vida de gracia en cada cristiano-Iglesia.

Siendo la misma Iglesia suceso-revelación, como tal se planta en la historia profana del mundo y del hombre-individuo. Es también la Iglesia, por lo mismo, proximidad de Dios al hombre y del hombre a Dios. El verdadero cristiano-Iglesia es el hombre que piensa y obra en la proximidad gratuita y absoluta de Dios en Cristo y por su vida 
se acepta envuelto por la gracia de Dios. No nos engañemos nunca: sólo desde el mundo de los hombres —en donde vive la Iglesia-, só. lo ahí es donde estamos unidos al Dios vivo. Así, el mundo, aun conservarido su forma profana, con sus leyes y estructuras humanas, con su finalidad propia, es campo de acción y santificación, porque todo él está inmerso en Dios por Cristo, dentro de la presencia del misterio profundo de su amor. Luego yo tengo que humanizar el mundo, santificándolo, a través de mi santidad propia, que se realizará dentro del mundo mismo. El mundo se me ha confiado a mí para incorporarlo en Cristo y entregarlo al Padre en desarrollo, haciendo de él con el testimonio de mi acción cristiana y santa una morada humana digna al servicio de cada hombre y de cada mujer.

Pero tampoco debemos pecar de angelismo o de un irenismo infantil. El mundo está tocado, manchado, en pecado. Y como tal debemos tomarlo, para lavarlo y presentarlo bien limpio al Padre en la parte que a nosotros nos corresponde actuar. Si está sellado de contingencia y caducidad, yo debo tomar consciencia de él al hacerlo progresar hacia el desarrollo y felicidad. La construcción del mundo y mis posibilidades de ennoblecerlo son limitadas y finitas, y las cosas participan de ambigüedad en lo que es humano y material. $Y$ siendo el mundo un no-Dios, una criatura, es una secularidad dentro de la historia, una discurrencia en el tiempo-historia.

No perdamos de vista una cosa. El mundo - volvemos a repetirlo- es contingencia, versatilidad, posibilidad. $Y$ dentro de esta cualidad de movilidad y transitoriedad, el hombre, que también está tocado de lo mismo, tiene que sudar y trabajar en un mundo así de contingente. Luego sus obras y su esfuerzo estarán atravesadas de la finitud y ambigüedad de todo lo material. Esto significa que el hombre, colocado en el centro del mundo, tiene que hacerlo caminar hacia Dios, Verdad pura, Bondad permanente y Bien absoluto, para hacer realidad la recapitulación de todo en Cristo ".

En este intento humano se da una expresión-abertura y significado de comunión entre el hombre y Dios. Y la Iglesia, como institución salvífica y sacramento de santificación-salvación, es la comprensión sagrada de esta comunión humano-divina. Pero tengamos

11. Ef. 1,10 
en cuenta que la Iglesia, en su relación con el mundo, no es algo ajeno a la realidad mundana. Compuesta por hombres del mundo, es el mismo hombre y el mundo mismo en unión con el Dios vivo. Luego el concepto eclesial y el concepto mundano son dos extremos que lle. gan a unirse y completarse en Cristo, a través del hombre-mundoIglesia. Por eso, la Iglesia no es ajena al mundo, como tampoco el mundo es extraño a la Iglesia. Es el hombre-Iglesia quien tiene que humanizar-divinizar al mundo, humanizándose-divinizándose más a sí mismo. El mundo es tierra a santificar; y es el hombre-Iglesia quien debe hacerlo.

Para esto hay que tomar el ejemplo de Dios creador, para quien las criaturas son asumidad, luego de creadas, en su amor. Es en el acto de la creación en donde se constituyen en seres reales terrenos y en donde son asumidas en la intimidad de Dios salvador. Dejarlas, sería ponerlas en la indiferencia de Dios; sería abandonarlas; y Dios las ama; y porque las ama, las sube hasta El. Lo mismo el hombre. Si se le plantó en el mundo para reinar sobre él, no debe dejar solo al mundo. Su reinado se comprende sólo en el servicio y servicio de amor fecundo y fecundante. Hacer que marche-progrese el mundo hacia su desarrollo, es tomarlo, subirlo-asumirlo, santificándolo. Y cuando lo santifica, el hombre se humaniza y humaniza al mundo. $Y$ santificarlo-humanizarlo es igual que introducirlo en el misterio de Cristo, que lo redimió.

\section{LA IGLESIA, SACRAMENTO DE SALVACIÓN}

Para la humanidad-sociedad lo que cuenta a la hora de buscar la unidad, su unidad formal, no puede serlo de origen antropológico, tiene que basarse en una comunidad de personas, en la que el sentimiento-racionalidad realice la comunión. Esta comunión sólo se logrará partiendo de los valores humanos auténticos, que son los únicos capaces de fundar la comunidad. Lo que equivale a afirmar que la unidad específica de la humanidad es la misma de vocación y destino. Y esta vocación-destino se expresa radicalmente en la comunión de todos los hombres dentro de la humanidad.

La revelación divina viene a constatar que esta tarea de realizar la comunión entre todos los hombres es una respuesta a la interven- 
ción gratuita y amorosa de Dios. Esta koinonía humana -comunidad de sentimientos para llegar a la comunión de haberes- es un don de Dios. Porque al comunicarse Dios de una manera absoluta, asimismo sz revela como valor vital más elevado y más profundo; y al mismo tiempo descorre a los hombres el velo para encontrarse a sí mismos como valor: les anuncia el contenido sobrenatural de que ellos son pueblo de Dios. Por el don de la creación y, más en concreto, por el don de la gracia-redención, la humanidad se hace más pueblo suyo que antes. Por eso, la comunión-unidad que Dios quiere es la Comunión de los Santos.

Pero esta Comunión de los Santos tiene que tener un centro, un medio, o un dentro-de-nosotros, que se convierta en el medio escogido por Dios para realizar la gran-asamblea-comunidad de los dispersos y de los centrados en un núcleo que se llame y sea realmente pueblo de Dios. Luego, la forma con que Dios realiza la comunidad entre los hombres es la de una mediación representativa: por un solo hombre, llamado y seleccionado entre los demás para ese fin, para la salvación de todos. La función representativa de ese hombre - Adán, Noé, Abrahán, Moisés, Israel, el rey, el Hijo del Hombre - tiene un papel especial, personal, en el Antiguo y Nuevo Testamento.

De hecho, Abrahán se siente claramente en selección, y responde a la llamada de Dios para ser padre-salvación de muchos pueblos. Moisés dentro del pueblo hebreo tiene conciencia de esa misma responsabilidad de representación y selección, aunque concretada a un clan o pueblo-nación. Más tarde, de una manera titubeante o en claridad, cada profeta, cada rey, cada sumo sacerdote, dentro de Israel, tiene y siente la misma vocación, y responde débilmente o al tope a la llamada de Dios. Y todos, aun los más nacionalistas hebreos, sienten ansias de salvación ecuménica. Bien claro aparece este deseo en los últimos profetas, sobre todo en los posteriores a la cautividad de Babilonia. Y esto a partir ya de Isaías.

Esta idea de mediación-salvación demuestra que los hombres son insuficientes para sí mismos, que son dependencia unos de otros; y al conceder Dios su salvación universal expresa esta condición de comunidad humana. La salvación de los hombres se realizará según el plan de Dios, sólo y únicamente a través y por medio de los hom- 
bres. San Pablo expresa esta salvación horizontalmente ${ }^{12}$, que viene hacia los hombres verticalmente: de Dios al hombre, a toda la humanidad. Esta salvación, vertical por parte de Dios y horizontal en favor de todos los hombres, sugiere una radicalidad soteriológica para los hermanos y dentro de los hermanos, a través de un servicio de fraternidad de hermano a hermano; pero siempre gracias a una elección divina. Al principio será escogido Israel-pueblo-nación ${ }^{13}$; y al final ya será el Mesías, un solo hombre, el Hijo del Hombre, Hijo de Dios en nombre de toda la comunidad humana.

Para nosotros-cristianos Jesús no es sólo (uno entre nosotros». Representa a Israel-humanidad, de una manera propia y más profunda que en la doctrina veterotestamentaria, porque es el Hijo del Padre de forma única y apropiada, que se hace hombre entre hombres y (seleccionado de entre los hombres" ${ }^{14}$, y (nnacido de mujer»" ${ }^{15}$. Está al servicio fraternal de los hombres. Por eso, «la gran asamblea de todos alrededor de Dios") ${ }^{16}$ se convierte, en Cristo y por Cristo, en una comunión recíproca de los hombres alrededor de Cristo, en una palabra, en la Iglesia-pueblo-de-Dios ${ }^{17}$. Es decir, la humanidad dispersa se agrupa en comunidad, en humanidad redimida en Cristo ${ }^{18}$. fundada en el hombre escatológico ${ }^{19}$, que es espíritu vivificante, es decir, no solamente un hombre, sino un hombre que se convierte en vida y que da vida abundantemente a los demás ${ }^{20}$.

Luego, el hecho histórico más importante para la humanidad es la presencia en el mundo del Mediador-Redentor-Mesías-CristoJesús. Porque el hecho de la salvación de Dios para la humanidad, no dejando de ser un gesto divino y sobrenatural, encaja perfectamente en la historia de los hombres. Porque esta voluntad divina se ha manifestado en el seno de la historia mediante la redención real y (objetiva), a través de la vida, pasión, muerte, resurrección y doctri-

12. "El primogénito de una muchedumbre de hermanos" (Rom. 8, 29). "Mi hijo primogénito" Ex 4, 22

13. 1 Sam. 7, 14; Sal. 2, 7

14. Hebr. 5,1

15. Gál. 4,4

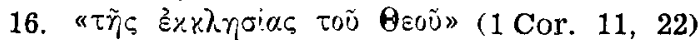

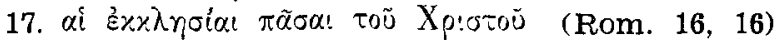

18. Ef. $1,10$.

19. En el Ёxatos 'A $\delta$ dip (1 Cor. 15, 45)

20. Jn. 10,10 
na de Jesucristo-Mesias, quien, apareciendo en la historia, es «uno entre nosotros), y que a nosotros representa ante el Padre. Así se ha formado la unidad en la humanidad; y la humanidad ha penetrado en el Padre, a través de la sangre redentora del que es (uno entre nosotros", uno mejor que nosotros y hermano de nosotros. Desde este nuevo gesto redentor de Cristo, la historia humana ha quedado consagrada por el Padre, por el hecho de que el Padre ha sentado a su derecha al Jesús-Humillado-Resucitado-Redentor, glorificándolo en su humanidad y coronándolo "Hijo de Dios en poder»"

Así, Cristo se convierte en el principio y fin, alfa y omega de la historia humana en su plenitud ${ }^{23}$. Y esto no sólo por su condición supra-histórica, o anhistórica, o supra-terrena, o trascendente a la historia, sino por ser Cristo historia humana, ser-hombre-histórico, que ha entrado en ella en la plenitud de los tiempos. En Cristo ya llegó la historia a su madure $z_{\uparrow}$ y alcanzó ya su realización definitiva y de una manera que durará por toda la eternidad. Jesús es el prototipo de nuestra historia humana,y por ser el primogénito entre los hombres, la historia ha entrado ya en la gloria. Por eso, traspasando El nuestra experiencia, es el sentido primero y último de nuestra historia, y es la explicación-clave de la misma. Por lo que San Agustín divide los sucesos humanos en dos grandes apartados: "anteriora Christi y posteriora Christi», antes y después de Cristo.

En realidad, Cristo ha dado un sentido nuevo a la historia en el marco inmanente de su humanidad y de nuestra humanidad. Pero si esto es muy cierto, hay una fuerte relación entre reunión-unidad humanidad y esa otra unidad-humanidad-Iglesia, que es humanidad renovada en Cristo y por Cristo. Y si esta distancia se considera desde dentro de esa "Iglesia de Cristo», la unidad-humanidad simple casi aparece disgregada, y casi no se ven más que individuos, a lo sumo, grupos aislados casi sin conexión unos con otros. Porque es en la Iglesia-reino en donde por y a través de la gracia-unión-santificación, gracia que justifica y santifica y unifica en comunión, se realiza la fraternidad humana por la implantación de Cristo en cada uno por la aceptación de la fe y el bautismo. Cuando un hombre entra a la Iglesia, la victoria de la gracia se convierte en un hecho objetivo e histó-

21. Rom. 1, 4

22. Apoc. 1,$8 ; 21,6$ 
rico. Esta misma entrada a la Iglesia indica la gran distensión-tensión dialéctica entre Iglesia y humanidad.

Pero, ¿es que la humanidad no ha sido ya redimida? $\mathrm{Si}_{\text {, lo ha }}$ sido y sobreabundantemente. Pero, lo que ocurre es que, si Cristo ha puesto ya por su parte su todo infinito, aún le queda a la humanidad, por la suya, lo que ella tiene que realizar: aceptar ese todo-infinitomensaje de Cristo al mundo. $\bar{Y}$ mientras no se realice este gesto humano, propio de la humanidad y exclusivo de ella, la redención-reunión-comunión plena no se conseguirá en el tiempo-historia.

Puede ocurrir que alguien pregunte: ¿pero, es que Cristo no intentaría introducir esta distinción entre Iglesia y humanidad, es decir, formar una porción de seleccionados y otra de no-escogidos? Porque la Iglesia, a primera vista, parece un pueblo de elección. Bueno, vamos por partes. En primer lugar, Cristo no trató nunca de hacer un grupo aparte en la humanidad con su Iglesia, una comunidad particular en medio del mundo. En su predicación no quiso reunir sólo un "resto», sino agrupar a todo Israel, para hacer con él el nuevo puebloreino de Dios. Si hubiera intentado lo contrario, su mensaje, intención y voluntad hubiera sido contrario a la del Padre en el plan universal de salvación. Si la salvación se ofreció primeramente a Israel, éste sólo fue un canal de donde partiría para toda la humanidad. A pesar de esto, Israel, en su totalidad, no aceptó la predicación pública del Mesías-Jesús. Y no sólo no la acıptó, sino que persiguió a muerte a Maestro y discípulos. Sólo cuando la oposición se abrió, y ya Cristo no podía aparecer en público es cuando Jesús se dirige al rebañito, a ese reducido grupo de discípulos en donde y con quienes construiría su Iglesia sobre la roca-firme-Pedro ${ }^{23}$. Y después de la resurrección es cuando ese grupo se constituye en reunión-Iglesia-de-Cristo, comunidad histórica visible en unión con Cristo-Cabeza-Firmeza.

Bajo el punto de vista de la humanidad, la muerte de Cristo sig. nifica un gesto de repulsa de la humanidad misma: en el sanedrín, por parte judía, y en Pilato, por parte de la gentilidad, e incluso por parte de la primera cristiandad en Pedro y en los otros discípulos, que abandonan al Maestro a su suerte fatal. Jesús en su sacrificio está solo, aplastado por la humanidad, solo en acto de servicio al Padre y a la humanidad, que reniega de El.

23. Mat. 16, 18-19; Jn. 21, 15-17. 
Esta muerte, si en realidad significa acercamiento al Padre y descenso de la gracia-redención, bajo el punto de vista humano, es también ausencia de Cristo, exigida, no por El, sino por la humanidad. La humanidad ha rechazado la Víctima, renegó de Cristo y acabó con El en el patíbulo: ruptura definitiva de la alianza de gracia. La humanidad, al renegar de Cristo ha rechazado cla venida del reino» a este mundo, y con ello la alejó de la comunidad humana. "Es cierto que toda muerte lleva consigo - dice Schillebeeckx - una ausencia corporal, la ruptura de las relaciones humanas con el difunto. Pero aquí se trata de la muerte de aquél que era el único capaz de traer salvación » ${ }^{24}$.

\section{LA IGLESIA, REALIDAD DE SALVACIÓN}

Para San Agustín está muy clara la presencia de Cristo-Iglesia o de la Iglesia-Cristo en el mundo, desde el comienzo del tiempo-historia. La Iglesia es tan antigua como el mundo, esa Iglesia que conocemos; porque la Iglesia está presente en el paganismo religioso; es precristiana en Israel, pueblo escogido, y es manifestación de Cristo como Iglesia de primogénitos ${ }^{25}$. Para San Agustín el reino de Dios tiene un desarrollo ascendente en la Iglesia, porque ella está presente en la vida y en la actividad de la humanidad religiosa ${ }^{26}$.

En el paganismo hay una consciencia de rectitud hacia lo sobrenatural; se presiente de una manera vaga la presencia de un Dios redentor, en quien hay interés por la salvación de cada hombre. Pero este sentir humano no fluye en claridad hacia una gracia liberanteactual, sino que queda en un fondo oscuro de presentimiento, y hundido en el fondo del corazón de cada hombre. Hay un diálogo anónimo con Dios. Hasta la misma vida, el-ser-hombre-en-el-mundo irá señalando a la humanidad cosas más nuevas cada vez.

Hasta los mismos sucesos naturales escuentran un diálogo interior de Dios al hombre, como forma vaga de revelación exterior, e

24. E. SchillebeeckX El mundo y la Iglesia, (Salamanca 1969), 239.

25. Hebr. 12, 23

26. S. AGUSTIN De peccat. meritis et remis. II, 11, 16; De perfect.just. hominis, 19, 42; De preadest, sanctorum, 9, 17-20; De Unico Bapt. contra Petil. 15, 26-27. 
incluye en sí un designio particular, que sobrepasa las posibilidades de la creación. Tan cierto es esto, tan cierto es que la gracia-interiorsalvación está viva en la humanidad, que el mismo paganismo es quien se esfuerza en darle una forma exterior a esa espera íntima por medio de todo el tinglado de pompa en su culto idolátrico. Es que el hombre está tan prendido de Dios, que hasta el mismo Dios no puede desprenderse del hombre.

Lo que ya no pudo hacer el paganismo fue desligarse de unas formas toscas -el paganismo o la razón humana-, que le impidieron ver con más claridad. $\mathrm{Y}$ al no apoyarse en una revelación particular y exterior de Dios, confunde lo auténtico con una parte de la humanidad en su deformación dogmática y en su desviación moral y hasta cultual. Todo el Antiguo y Nuevo Testamento son testimonio de la preocupación de Dios por los pueblos no-hebreos, por el paganismo. Porque el hombre se encuentra siempre en abertura plena, en relación íntegra de yo-tú, en diálogo constante. Pero con frecuencia sucede que un algo le impide la unión vital-integral del yo-tú, y no logra encontrar la causa que desvía esa relación vital del yo-tú por sí mismo. Se considera en la situación del hijo desgajado del árbol de familia; y hasta que no se incorpore a él, no sentirá la claridad de la presencia del Padre y de la auténtica familia.

Desde el lado de Israel se ve palpitar el ansia de relación a Dios por parte del hombre, y mucho más intensa por parte de Yahvé. Siempre en zozobra, no logra Israel despegar las cataratas que impiden la claridad de la gracia. Desde el fondo de sí una oscuridad le entenebrece la razón, a pesar de que el sentimiento le dicta la presencia intima y cercanísima de un algo que no sabe lo que es, pero que necesita para hacerse más pueblo-persona-racional. La comunidad pagana, animada por algunas figuras-cumbre, alimentaba la vida religiosa de los miembros; y esto constituye ya una Iglesia en el anonimato, una porción anónima, que camina hacia Dios desde su lado humano en penumbra. Así, la Iglesia, como presencia de Dios, viene a ser una realidad tan amplia como la humanidad. Pues, toda gracia está vinculada a la promesa del Mediador-Redentor, o a la realidad de Cristo-Mesías.

Esta gracia-presencia-de-Dios en la Iglesia-mundo sólo se manifiesta claramente en la revelación personal del mismo Dios, primero a Israel y luego a todo el mundo a través de su Iglesia. Son los be- 
duinos de Israel, recién salidos de Egipto, los que se reúnen en torno al Enviado de Dios, para formar la caravana del Exodo y crismarse como pueblo de Dios. De los diversos clanes familiares se formó una sola familia-clan, generándose el pueblo único de Dios-Salvador. Es en el desierto en donde nace Israel en torno al caudillo-Moisés, de inspiración divina. Pero es Yahvé el que manda a Moisés que reúna a su pueblo en una sola idea: Yo soy su Dios y ellos son mi pueblo ${ }^{27}$.

Israel es el prólogo a la gracia-Iglesia, y es fruto de la intervención directa de Dios. Es lo que hará Cristo también con su Iglesia que la amó "y se entregó El mismo por ella, con el fin de santificarla y purificándola con el bautismo de agua, con la palabra que la acompaña, para presentar ante sí mismo ésta, su Iglesia gloriosa sin mancha ni arruga ni cosa parecida, sino santa e inmaculada) ${ }^{28}$.

Israel es prólogo a la Iglesia, cierto; pero lo es con todo lo que tiene: con su culto, con sus sacerdotes, con su Ley y con su mensaje al mundo. Es Israel sacramento de la Iglesia, signo visible de la comunidad-Iglesia-visible de los creyentes, que se reunirán en torno a Cristo en otra familia universal y no cerrada por los débiles lazos de sangre en un clan familiar. Con todo, Israel es signo externo de la gracia, de la gracia-amor de Yahvé, signo de gracia santificante, no en cuanto energía de acción santificante, sino porque Israel era ya por sí mismo parcial realización del misterio-Cristo-Mesías; e Israel era signo y causa de gracia en la medida en que anunciaba a Cristo-Futuro-Promesa. Pero con todo, por ser sólo figura, no podía dar a plenitud la realidad de la gracia. Era sólo presencia imperfecta del misterio de Cristo. Israel daba la gracia de una abertura al Mesías, que había de llegar: una gracia de adviento, de promesa, de llegada.

La misión de Israel será vivir a la manera de pueblo de Dios; y sólo en cuanto viva esta idea fecunda será Yahvé su Dios e Israel será su pueblo ${ }^{29}$. Dios será fiel en su alianza. Será Israel el culpable de la ruptura del pacto. En cuanto esté en relación con Yahvé a través de la alianza pactada con $\mathrm{El}$, en eso será Iglesia-salvación. La revelación, en el Antiguo Testamento, se va desarrollando dentro del marco histórico de la fidelidad de Israel a Yahvé, con su fidelidad y sus pre-

27. Ez. 16, 3-9

28. Ef. $5,25-27$

29. Ex. 6, 5; Lev. 26, 12 ; Dt. 26, 17-18; 29, 12-13; Jer. 7, 23; Ez. 11, 20; $14,11-37,27$; Os. $1,9$. 
varicaciones-tupturas para con su Dios-salvación. Dios quiere para sí un pueblo totalmente a su disposición. Y dentro de esta tensión dialéctica de Israel-Yahvé, se va realizando la revelación. Pero Israel fracasa en esta fidelidad a Dios; $y$, de fracaso en fracaso, cayéndose y levantándose, irá tejiendo su historia, hasta que aparezca un hombre, en quien se concentre una invitación universal a la humanidad a la fidelidad a Dios. Cristo mira hacia las dos partes del mundo: a la fiel y a la infiel. Y el diálogo fallido entre Dios y la humanidad se reanudará en y por Jesús-Mesías con una respuesta esencialmente lograda. En Jesús, una y única persona, existe la invitación de Dios y la respuesta fiel del hombre, porque el mismo Cristo es Alianza cumplida y sellada con su sangre.

Ya en el seno desarrollado de la Iglesia-pueblo-de-Dios, Jesús-el Hombre se hizo gracia visible, presencia sensible de Dios, gracia victoriosa. Pero Jesús no sólo es gracia-donación-de-Dios, o si se quiere visibilidad de gracia ofrecida, sino también claridad de aceptación perfecta de esa gracia-ofrenda por parte del hombre. Es realización plena de la relación Dios-hombre y de hombre-Dios. Cristo es el reino y rey del reino. Es Iglesia manifestación visible y personal de la gracia elevante-redentora. Por eso, sólo hay Iglesia en y por Cristo, como sólo hubo Israel en y por la alianza-pacto-Mesías. La humanidad de Jesús es, por eso, sacramento visible en el que el misterio del amor salvador de Dios se ha desvelado a todos, y por el que Dios-salvación nos ha hecho entrar a ese amor suyo. En este amor se reúne -concepto eclesial - toda la humanidad.

Luego, la Iglesia es el punto más visible de la concentración de los reunidos en el amor de Dios. Y si la Iglesia está en el hombre -en cada hombre-, y si en el mundo se da esa concentración de los hijos del amor de Dios, el mundo es la Iglesia; y la Iglesia no es ajena al mundo en ninguna manera. La Iglesia para el mundo será el lugar de acervo de gracia, el foco de irradiación de la gracia, punto de concentración de los dos amores, del amor de Dios y del amor del hombre en correspondencia a esa infinita entrega de Dios al hombre.

Es la Iglesia la comunidad visible de la gracia; y es, al mismo tiempo, un signo terreno de la gracia triunfante de Cristo, del Cuerpo Místico de Cristo, compuesto de cabeza y miembros, de jerarquía $\mathrm{y}$ obediencia. $\mathrm{Y}$ las dos, inseparada e inseparablemente, jerarquía y obediencia, autoridades y súbditos, son Iglesia, e Iglesia de Cristo, 
partes de ese signo elocuente y cargado de gracia. La Iglesia -clérigos y laicos- es la manifestación maravillosa ante la historia de la victoria alcanzada por Cristo para la humanidad, victoria de reconciliación de la humanidad con el Padre a través de Cristo. La Iglesia es là gracia de Cristo "presente común») en el mundo. Y si es gracia, no es un medio de salvación, sino salvación auténtica, forma visible, externa, corporal, de salvación.

Así, la Iglesia, como tal, es santa. "Todo lo que ha nacido de Dios, no comete pecado" ${ }^{30}$; pues, "sabemos que todo el que ha nacido de Dios no peca) ${ }^{31}$. Esto lo refiere San Juan a la Iglesia, como realidad concreta. Pues, ¿y los cristianos? El mismo San Juan afirma de los cristianos: " $\mathrm{Si}$ decimos: no tenemos pecados, nos engañamos» '.2. ¿Qué quiere decir San Juan? Que en la Iglesia no todo acaba aún por ser Iglesia. Que en la Iglesia, salvación en forma visible, signo apretado de realidad salvífica, los miembros de esta Iglesia aún pueden sustraerse a su influencia santificadora; y en la medida en que uno peca, deja de ser Iglesia-salvación. Introduce dentro de sí, estando en la Iglesia, una desgarradura entre el signo y la realidad significada. Es que la Iglesia aún no ha llegado a su última fase en el pleroma de salvación; es que aún camina en el tiempo-historia; y aquí los que son Iglesia pueden dejar de serlo, por el desgarramiento que produce su pecado personal dentro del seno familiar del Cuerpo Místico de Cristo.

Ya en el final, en el cielo, al fiinal del tiempo-historia, alcanzará su edad plena en la plenitud de santificación-salvación. La resurrección de la carne y la parusía del Señor Jesús sellarán su forma definitiva de salvación en los cuerpos y en las almas, la totalidad humana dentro de su personalidad racional. Y solamente entonces manifestarä plenamente y para siempre, en visibilidad externa, su propia y esencial santidad.

Moisés M." Campelo,

30. $1 \mathrm{Jn} .3,9$

31. $1 \mathrm{Jn}, 5,18$

32. $1 \mathrm{Jn} .1,18$ 